\title{
Retroactive interference as a function of set and recall environment'
}

CECIL A. ROGERS, JR, ${ }^{2}$

TULANE UNIVERSITY

The Incidental-Intentional Training paradigm was proposed to effect rapid verbal forgetting via retroactive interference. After word association to a 5-word list, Ss studied a similar list. At 2 min., free recall of the first list yielded only $11 \%$ correct responses with $54 \%$ other-list intrusions. This decrement was attributed to interaction of inadequate set and an impoverished recall environment. In another group $S s^{\prime}$ idiosyncratic word associations appeared on the recall page to enrich the recall situation by functioning as reminders. Here, correct recall was $75 \%$ with only $16 \%$ other-list intrusions. Possible reasons for imperfect recall in the latter group were enumerated.

Since Underwood (1957) and Underwood \& Postman (1960) there has been increasing emphasis and research on proactive sources of interference in verbal memory. This trend is marked and has been accompanied by a number of methodological innovations with the effect that larger quantities of proactive interference are now being obtained in the laboratory. The largest magnitude reported to date was by Blick(1965) who capitalized on pre-experimentally established language habits as revealed by free association norms. By providing stimuli on the recall page which evoked competing responses, Blick's procedure produced up to $54 \%$ interference over a $2 \mathrm{~min}$. retention interval.

The presently reported study evaluates a new method of inducing forgetting by producing retroactive rather than proactive interference. This design is called the Incidental-Intentional Training Paradigm and, as the name suggests, requires training $S$ first upon a relatively incidental task, then upon an intentional task, followed after a specified retention interval by recall of the incidentally trained materials.

If equal levels of difficulty, meaningfulness and other relevant variables obtain for the two tasks, it is expected that practice on the second task will interfere with recall of the first. Whether such interference would obtain is important to determine, in that at present no retroactive designs exist which compare to the demonstrated power of proactice methods for producing forgetting. Indeed, it has been questioned whether retroactive interference can play a major role at all in theories of forgetting (Underwood, 1957).

The choice of pitting incidental against intentional training was derived in part from McGeoch \& Irion (1952) who suggest (1) inadequate set to remember and (2) altered stimulus conditions in the recall environment to be major prerequisites for forgetting to occur. The production of inadequate set in verbal learning often rests largely with the instructions. Thus, other things being equal, if $S$ is requested first to "cancel the vowels" in a word list, then to study a second list, he enters recall with both a lack of set to produce the first words and an antagonistic set to recall the second list. Impoverishment of the recall environment is common practice and easily accomplished by providing only a blank page for free recall. This alternation can be reduced and conditions more similar to training reinstated by procedures such as recognition, repeating the stimuli when $S$ was trained on several $S-R$ pairs or, for a single list of words, presenting a portion of the list in recall and asking $S$ to complete it. The training paradigm used in the present study employs both the McGeoch and Irion considerations. Using verbal booklets, two groups of Ss were asked to produce word associations to one list of words, then to study a second list of words, and after a 2-min. retention interval to recall the first list. It was expected that the Free Recall group would exhibit severe forgetting. On the other hand, a Stimulated Recall group, whose idiosyncratic associates were conveyed to the recall page, were expected to overcome this deficit. If the latter group did not show improved recall, it might be doubted that either group learned the first list originally. Further, the degree of facilitation in recall achieved with improved stimulus situation should offer some glimpse as to the relative potence of the set and stimulation variables. Method

Subjects. A total of 160 Keesler AFB trainees were unsystematically assigned to two groups and tested simultaneously, after which groups were equalized at 70 each by random voiding.

Materials and Procedure. Six-page verbal booklets previously described (Bilodeau, Fox, \& Blick, 1963) were arranged in the following manner: cover page, instruction page, 1st training page, 2nd training page, vowel cancellation page, recall page. The instruction page described word association procedures and presented examples. On the next page (page A) all Ss were presented a 5-word list and asked to print to the left of each item "a word which would remind you of that item." On the third page (page B) was a similar unrelated 5-word list which Ss were simply instructed to "study." Following a vowel cancellation page was the recall page, whereupon, all Ss were instructed to recall the first list of items which they had seen on Page A. The Free Recall (FR) group was provided five lines on which to write their answers. The Stimulated Recall group (SR) Ss had in addition their five idiosyncratic 
Table 1. Correct Recall and Sources of Misrecall by Group

\begin{tabular}{lcccc} 
Group & $\begin{array}{c}\text { Correct } \\
\text { Response* }\end{array}$ & $\begin{array}{c}\text { Same-list } \\
\text { Intrusion }\end{array}$ & $\begin{array}{c}\text { Other-list } \\
\text { Intrusion* }\end{array}$ & Remoinder \\
\cline { 1 - 1 } & .75 & .01 & .16 & .03 \\
SR & .11 & .16 & .54 & .19 \\
\hline FR & .11 &. & .01
\end{tabular}

* Group Differences are Significant with $p \leq .01$.

word associations which were conveyed to the recall page by the use of no-carbon-required papers (Bilodeau \& Fox, 1965). E-paced time allotments per page were $30,60,30,90$, and $120 \mathrm{sec}$. respectively.

Words chosen were 10 noun-primaries from recent norms (Bilodeau \& Howell, 1965), selected such as to minimize inter- and intra-list associations. They were arranged into two 5-word lists, each in two sequences, thus producing four list variations. One quarter of the Ss per group were assigned to each of these variations on page $A$; the alternate list then appeared on page $B$. The following words were selected: flower, song, sky, chair, water for one list and ground, lamb, insect, queen, grass for the other list.

\section{Results and Discussion}

A glance at Table 1 indicates first that the paradigm did produce forgetting in the FR group to the extent of $11 \%$ correct responses in the correct position. This $89 \%$ forgetting is further broken down into sources. Sixteen per cent of the responses were merely misplaced (right word but in wrong order). The largest single source of errors was retroactive interference produced by Page B which resulted in 54\% other-list intrusions. This figure is comparable to that $54 \% \mathrm{max}-$ imum amount of proactive interference previously obtained by Blick (1965). Blanks and non-allocated responses accounted for the remaining $19 \%$ loss. In sum, the Free Recall group, laboring under inadequate set and an impoverished recall environment remembered quite poorly over a 2-min. retention interval with their largest source of misrecall due to competing retroactive responses.

Granted that massive misrecall was obtained, it is necessary to determine whether the incidentally trained items were learned to begin with. A cursory examination of Group SR's performance in Table 1 indicates that learning did occur. Here, when word association reminders were present on the recall page, there was $75 \%$ correct recall $176 \%$ if same-list intrusions are included). That this $64 \%$ increment in remembering was not greater may be due to several reasons: (1) incom- plete learning of list $A$; (2) occasional dominance of stronger list $B$ responses, in that they intruded with a probability of .16 even under these improved recall conditions; (3) a lack of sufficient potence of Ss' reminders to overcome the set variable. The degree of original learning could be more accurately assessed with the addition of a group having immediate recall after the incidental task, as was suggested by Irion (1948).

The generality of the paradigm has been extended by Fox (1966) who obtained over $70 \%$ retroactive inhibition in a motor-skills printing task; however, the need for variations in verbal materials and types of tasks is apparent. With these limitations in mind the data as a whole are congruent with predictions and support the McGeoch \& Irion (1952) emphasis on set and recall environment as important determiners of forgetting. Conversely, the substantial a mount of forgetting obtained suggests that proactive designs are not inherentiy more powerful than retroactive ones. Further research is demanded and, if findings are congruent with the present data, a re-evaluation of the relative roles of pro- and retroactive agents in forgetting may be required.

\section{References}

Bilodeau, E. A., \& Fox, P. W. The NCR booklet: A group technique for studying word arousal phenomena as a function of $S^{\prime}$ 's idiosyncratic habits. Psychon. Sci., 1965, 2, 223-224.

Bilodeau, E. A., Fox, P. W., \& Blick, K. A. Stimulated verbal recall and analysis of sources of recall. J. verbal Learn. verbal Behav., 1963, 2, 422-428.

Bilodeau, E. A., \& Howell, D. C. Free association norms. Tech. Rep. No. 1, Nonr contract 475(10) to Tulane University, 1965.

Blick, K. A. Cultural primaries as a source of interference in short-term verbal retention. J. exp. Psychol., 1965, 69, 246-250.

Fox, W. L. Retention of a simple motor-skills task. Unpublished doctoral dissertation, University of Arizona, 1966.

Irion, A. L. The relation of 'set' to retention. Psychol. Rev. $1948,55,336-341$

McGeoch, J. A., \& Irion, A. L. The psychology of learning. New York: Longmans and Green: 1952.

Underwood, B. J. Interference and forgetting. Psychol. Rev., 1957 $64,49-60$.

Underwood, B. J., \& Postman, L. Extra-experimental sources of interference in forgetting. Psychol. Rev., 1960, 67, 73-95.

\section{Notes}

1. The data reported herein served as part of a dissertation submitted to Tulane University in partial fulfillment requirements for the Ph.D. degree. This research was supported by a National Science Foundation fellowship and a PHS (NIMH) fellowship to the author, and by a Nonr grant No. $475(60)$ to E. A. Bilodeau. The aid of E. A. Bilodeau is gratefully acknowledged.

2. Now at University of Arizona. 